\title{
Test yourself: a 49-year-old lady with a history of chronic left hip pain following a fall twenty months earlier
}

\author{
Muhammad Dharas $^{1} \cdot$ Petra Balogh ${ }^{2} \cdot$ Michele Calleja $^{1} \cdot$ Asif Saifuddin $^{1}$ \\ Published online: 5 April 2020 \\ (C) ISS 2020
}

Question: Left-sided hip pain and reduced range of motion.

Answer: Intra-articular calcium pyrophosphate deposition disease (CPPD).

MRI of the pelvis shows a soft tissue mass at the anterosuperior aspect of the left hip extending to the level of the anterior superior iliac spine, possibly representing an avulsion injury (Fig. 1). Other differential diagnoses for a lowintermediate signal intensity intra-articular mass include tenosynovial giant cell tumour and synovial osteochondromatosis. CT was undertaken for further characterization, this demonstrating a diffusely mineralized intraarticular mass eroding the anterior aspect of the acetabular roof and extending distally to the femoral head-neck junction, with no appreciable bone continuity to either the acetabulum or femoral head (Fig. 2).

MRI of the hip showed a heterogeneous, well-defined low signal intensity soft tissue mass appearing to extend from an erosion at the base of the anterior superior iliac spine. The combination of findings was felt to suggest an underlying diagnosis of gout or calcium pyrophosphate dihydrate disease (CPPD), but a mineralizing intra-articular soft tissue tumour such as synovial sarcoma could not be excluded. Therefore, CT-guided core needle biopsy was undertaken. This showed cores of fibrous tissue with diffuse deposits of CPPD surrounded by a granulomatous infiltrate including foreignbody giant cells and macrophages (Fig. 3a). Rhomboidshaped crystals were seen under polarised light (Fig. 3b). CPPD crystals are weakly birefringent compared with

The case presentation can be found at doi:10.1007/s00256-020-03427-7

Muhammad Dharas

muhammad.dharas@nhs.net

1 Imaging Department, Royal National Orthopaedic Hospital, Brockley Hill, Stanmore HA7 4LP, UK

2 Department of Histopathology, Royal National Orthopaedic Hospital, Brockley Hill, Stanmore HA7 4LP, UK monosodium urate under polarised light. Recognition of the crystal is based on shape and birefringence. Depending on the axis of orientation with respect to the polarizer, the colour of the crystal may change; blue if the polarizer is parallel to the axis of the crystal and yellow if perpendicular.

Intra-articular fibrocartilage calcification is the commonest imaging manifestation of CPPD [1]. Factors which predispose to CPPD include older age, genetics, osteoarthritis and the use of certain medications [2]. It can be diagnosed in most cases with a combination of clinical and radiological correlation [3], but rarely presents as an intra- or extra-articular, calcified tumour-like lesion within the joints of the extremities such as the wrist [4] and knee [5]. The temporomandibular joint is the commonest joint involved [6], and the hip is rarely involved.

Radiologically, tophaceous pseudogout presents as a calcified mass. A fluffy or granular calcified pattern may be observed, and occasionally there is evidence of mass effect with pressure erosion on adjacent bones. Distinguishing CPPD from common differential diagnoses is important. For example, chondrosarcoma calcification demonstrates a ring and arc pattern, in contrast to CPPD which presents an amorphous or cloud-like pattern [7].

Ossifying intra-articular masses represent a variety of pathologies. Synovial chondromatosis, tumoral calcinosis, synovial sarcoma and chondrosarcoma [8] all remain within the differential diagnosis [9]. Since CPPD can mimic soft tissue tumours, it is vital to determine the benign or malignant nature of the lesion in order to avoid inappropriate patient management [10]. Therefore, needle biopsy should be undertaken when the diagnosis is uncertain. Often patients with CPPD (either in its common or tophaceous form) are managed conservatively once clinical symptoms are controlled, whilst some elect for excision and show no recurrence of symptoms.

\section{Compliance with ethical standards}

Conflict of interest The authors declare that they have no conflict of interest. 


\section{References}

1. Edgar A, Zamora EA, Naik R. Calcium pyrophosphate deposition disease (CPDD). Treasure Island: StatPearls Publishing; 2019.

2. Abhishek A. Calcium pyrophosphate deposition disease: a review of epidemiologic findings. Curr Opin Rheumatol. 2016;28(2):133-

3. Freire V, Moser TP, Lepage-Saucier M. Radiological identification and analysis of soft tissue musculoskeletal calcifications. Insights Imaging. 2018;9(4):477-92.

4. Nakamura O, Kaji Y, Yamagami Y, et al. Rare case of tumoral calcium pyrophosphate dihydrate crystal deposition disease of the wrist joint. Case Rep Orthop. 2015;313291.

5. Watura C, Saifuddin A. Tophaceous calcium pyrophosphate dihydrate deposition disease of the knee mimicking an aggressive soft tissue tumour. BMJ Case Rep. 2014:bcr2014203998.

6. Hotokezaka Y, Hotokezaka H, Katayama I, et al. A case of tophaceous pseudogout of the temporomandibular joint extending into the cranium. Oral Radiol. 2019. https://doi.org/10.1007/ s11282-019-00410-4 [Epub ahead of print].

7. Hama S, Yasuda M, Minato K, Miyashita M, Chikugo T. Tophaceous pseudogout in the index finger. Journal of Hand Surgery Global Online. 2019;1:39-42.

8. Lambrecht N, Nelson SD, Seeger L, Bose S. Tophaceous pseudogout: a pitfall in the diagnosis of chondrosarcoma. Diagn Cytopathol. 2001;25(4):258-61.

9. Sadiq M, Nayak M, Farheen A, Digge V. An unusual case of huge tophaceous pseudogout mimicking as a tumor-like lesion around the ankle joint: a case report and literature review. Case Rep Orthop. 2019;25(2019):9617184.

10. Erhardt MA, Vetter SY, Suda AJ, Wentzensen A, Frank CB. Mimicry in older patients: tophaceous pseudogout as a tumor-like lesion: a case report. J Am Podiatr Med Assoc. 2011;101(5):462-5.

Publisher's note Springer Nature remains neutral with regard to jurisdictional claims in published maps and institutional affiliations. 